\title{
Locking Plate Osteosynthesis for Distal Radius Fractures
}

\author{
Sanjeev Kumar ${ }^{1}$, Ritesh Kumar², Bhupesh Patel ${ }^{3 *}$ \\ ${ }^{1} \mathrm{CMO},{ }^{2} \mathrm{GDMO}$, Department of Orthopaedics, North DMC Medical College and Hindurao Hospital, Delhi, India. \\ ${ }^{3}$ Consultant Orthopaedician and Spine Surgeon, CIMS Hospital and HCG Hospital, Ahemdabad, Gujarat, India.
}

\begin{abstract}
Introduction: Fracture of distal end radius is a common problem having various methods of treatment. Open reduction and plating maintains the fractured fragments in position till healing. This study is done to evaluate the results of locking plate fixation in distal end radius fractures.

Materials and Methods: This is a prospective and retrospective study conducted in the Saifee Hospital. It includes a study of 36 cases of fracture lower end radius operated with locking plate from Aug 2011 to Nov 2013. The patients were classified according to Gartland and Werley Classification. For statistical analysis we used a students 't' test with $95 \%$ confidence intervals. Significance was set at $P=0.05$

Results: 23 (63.90\%) was affected by the type III fracture as per Gartland \& Werley classification. 12 patients (33.30\%) had Type I fracture while 1 patient $(2.80 \%)$ had type II fracture. We achieved excellent results for 5 patients $(13.90 \%)$, while 27 patients $(75 \%)$ got good results. The commonest complication reported was Tenosynovitis / Tendon Adhesion (11 cases). The other common complications found were 8 cases of DRUJ Tenderness and 4 cases had hardware related complaints. The surgical technique is important in reducing complications.
\end{abstract}

\section{INTRODUCTION}

Fractures of distal end radius account for one sixth of all fractures that are seen and treated by orthopaedic surgeons.1,2 For decades, the primary treatment method for distal radius fractures was with plaster cast, but this treatment modality frequently leads to early loss of reduction and poor functional outcome, with intraarticular fractures being at particularly high risk. Universal cast treatment gave way to bridging external fixator, which in turn was replaced by dorsal buttress plating. Other methods include percutaneous pinning, bone grafting, fragment specific fixation and arthroscopic assisted fixation. Functional recovery closely parallels the accuracy of skeletal restoration and its maintenance especially for intra-articular fractures. Plating is an outstanding technique to restore and maintain the radial length and prevention of metaphyseal collapse. Loss of reduction is the most common complication which can be prevented with locking plate osteosynthesis. The objects of the present study are to evaluate the results of locking plate for fractures of lower end of radius.
Conclusion: Patients have good outcome provided that correct and precise surgical technique is used, proper anatomical reduction of articular fragment and buttressing with locking plates are done.

Keywords: Locking, Distal Radius Fractures, Gartland and Werley Classification.

\section{${ }^{*}$ Correspondence to:}

\section{Dr. Bhupesh Patel,}

Consultant Orthopaedician and Spine Surgeon

CIMS Hospital \& HCG Hospital,

Ahemdabad, Gujarat, India.

\section{Article History:}

Received: 08-10-2018, Revised: 03-11-2018, Accepted: 22-11-2018

\begin{tabular}{|l|c|}
\hline \multicolumn{2}{|c|}{ Access this article online } \\
\hline $\begin{array}{l}\text { Website: } \\
\text { www.ijmrp.com }\end{array}$ & Quick Response code \\
\hline DOI: & \\
10.21276/ijmrp.2018.4.6.054 & \\
\hline
\end{tabular}

\section{MATERIALS \& METHODS}

This was both prospective and retrospective study conducted in the Saifee Hospiatal, Mumbai in the Department of Orthopaedics. This study was approved by the ethical committee of Saifee Hospital. It includes a study of 36 cases of fracture lower end radius operated with locking plate from Aug 2011 to Nov 2013.

The inclusion criteria include adults $>18$ years of age of patients with simple closed intraarticular or extraarticular distal radius fracture, medically fit patients and patients willing for surgery.

The exclusion criteria were pathological fractures, patients with mental retardation and/or drug dependency, patients participating in other clinical trials of a drug or device or patient not willing for surgery, distal neurovascular deficit, severe soft tissue and open injury, patient with poor general condition and anaesthetic risk and patient with manifest infection. All patients were thoroughly examined. Relevant clinical findings, open injuries, other skeletal injuries were duly recorded in the patient proforma. Patients were 
posted for surgery after medical fitness, till then immobilized in below elbow slab. Radio graphs - Postero-anterior and lateral views taken. In selected cases CT scan with $3 \mathrm{D}$ reconstruction was done to improve the understanding of fracture pattern.

For statistical analysis to compare the relationship between radiographic outcome and functional scores, we used a students ' $t$ ' test with 95\% confidence intervals. Significance was set at $P=0.05$. The patients were classified according to Gartland and Werley Classification (1951) ${ }^{3}$

Table 1: Distribution of fracture pattern

\begin{tabular}{lc}
\hline Classification & Radiographic appearance \\
\hline Type I & Extra articular, Displaced \\
Type II & Intra articular, Non displaced \\
Type III & Intra articular, Displaced \\
Type IV & Extra articular, Non displaced \\
\hline
\end{tabular}

\section{Surgical Technique}

14 patients $(38.90 \%)$ were operated within two days of occurrence the injury. Total 25 patients $(69.44 \%)$ were operated within four days of the injury.22 patients were operated under general anaesthesia and 14 were operated under brachial and axillary block. After anesthesia, patient's forearm in a side attachment, skin incision was taken just lateral to the flexor carpi radialis tendon and medial to the radial artery. Flexor carpi radialis tendon was retracted medially while radial artery was retracted laterally. Pronator quadratus was raised from the lateral border of distal radius and retracted medially to expose fracture fragments. Fracture was reduced by traction and manipulation as per fracture displacement under direct vision. However articular alignment, radial length, radial inclination and volar tilt were confirmed under image intensifier. Reduction was held temporarily by kirschner wire followed by placement of volar locking plate. Final fixation was done with appropriate sized locking screws and fracture reduction and fixation was confirmed under image intensifier in AP and lateral view.

In our study we have used both fixed angle and variable angle locking plates developed by AO/ASIF and Zimmer. Both the plates are designed to provide angular stability, adequate buttressing and load sharing support to prevent collapse of fragments to overcome most of the main hardware problems. In these plates the screws which we used are locked into the plate and cannot back out or toggle. The plate thus acts as an external fixator put internally. The screws alternately diverge and converge improving the purchase in the metaphyseal area of distal radius. The crossed screws increase the pull out strength. We used volar locking plate in 25 , variable angle fragment specific locking plates in 10 and dorsal locking plate in 1 patient. 30 patients (83.3\%) were operated without additional fixation. However, for 5 patients (13.9\%) we used additional fixation in the form of kirschner wire. Closure of wound was done. Sterile dressing and splinting was done. Patients were discharged from the hospital on an average of 3 days. Follow-up of the patients were kept at 2 weekly intervals for suture removal and thereafter for one month, three months and one year. Post op assessment was done by using Gartland and Werely's demerit scoring system which include residual deformity, subjective evaluation, objective evaluation, and complication. Final outcome graded as excellent, good, fair and poor.

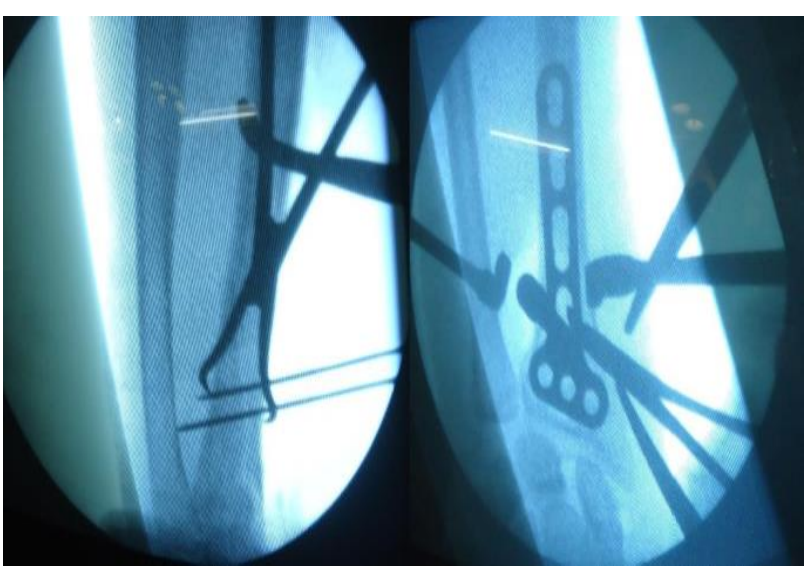

Figure 1: Intraop C arm images showing reduction and plate positioning

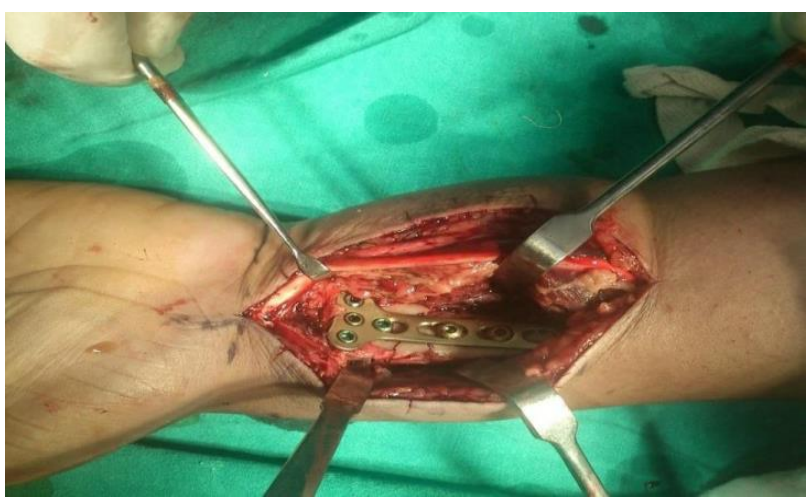

Figure 2: Final position of plate

Table 2: Age distribution

\begin{tabular}{lcc}
\hline Age (Years) & Frequency & Percent \\
\hline less than 20 & 2 & 5.6 \\
$\mathbf{2 0}$ to 39 & 16 & 44.4 \\
$\mathbf{4 0}$ to 59 & 15 & 41.7 \\
$\mathbf{6 0}$ and above & 3 & 8.3 \\
Total & 36 & 100 \\
\hline
\end{tabular}

Table 3: Gender distribution

\begin{tabular}{lcc}
\hline Gender & Frequency & Percent \\
\hline Female & 8 & 22.2 \\
Male & 28 & 77.8 \\
Total & 36 & 100 \\
\hline
\end{tabular}

Table 4: Gartland and werley type

\begin{tabular}{lcc}
\hline Gartland Werley (Type) & Frequency & Percent \\
\hline I & 12 & 33.3 \\
II & 1 & 2.8 \\
III & 23 & 63.9 \\
Total & 36 & 100 \\
\hline
\end{tabular}

\section{OBSERVATIONS AND RESULTS}

In our study, minimum age of patient is 18 years while maximum age was 70 years. The highest number of patients fell in the age group of 20 to 39 years (16) and the second highest were from 40 to 59 years of age. Males were $28(77.80 \%)$ and 8 were women (22.20\%). 19 (52.80\%) fractures were on right limb and 17 (47.20\%) on left side. 
Out of 36 patients, $23(63.90 \%)$ had been injured by RTA, whereas $7(19.40 \%)$ had sustained injury due to fall from height and remaining due to domestic fall. Out of 36 patients, 17 $(47.20 \%)$ patients had only distal radius fracture and 14 patients (38.90\%) had associated ulna styloid fracture on the same side of distal radius fracture. The common associated injuries were opposite radius fracture, other long bone fractures and head injury.

$23(63.90 \%)$ was affected by the type III fracture as per Gartland \& Werley classification. 12 patients (33.30\%) had Type I fracture while 1 patient $(2.80 \%)$ had type II fracture.

The results of radiological evaluation revealed that on the final follow up, our patients achieved $9.61 \mathrm{~mm}$ mean radial length, $4.22^{\circ}$ average volar tilt and $21.53^{\circ}$ of average radial inclination.

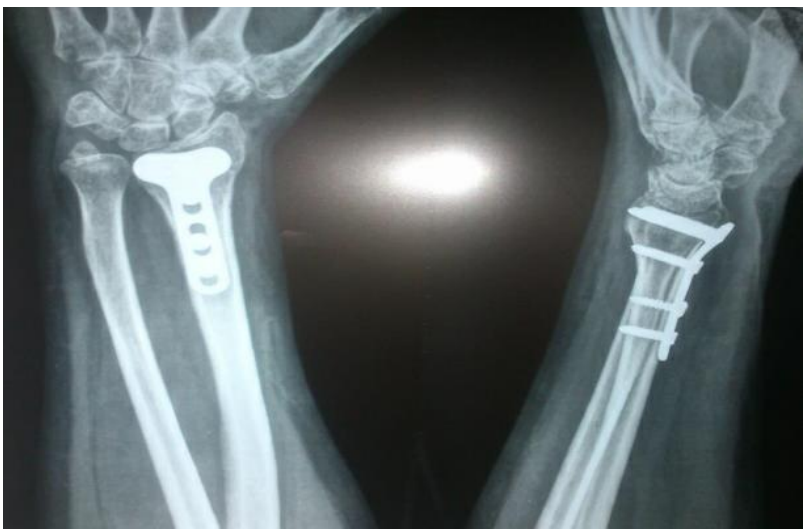

Figure 3: Post op $\mathrm{x}$ ray showing union

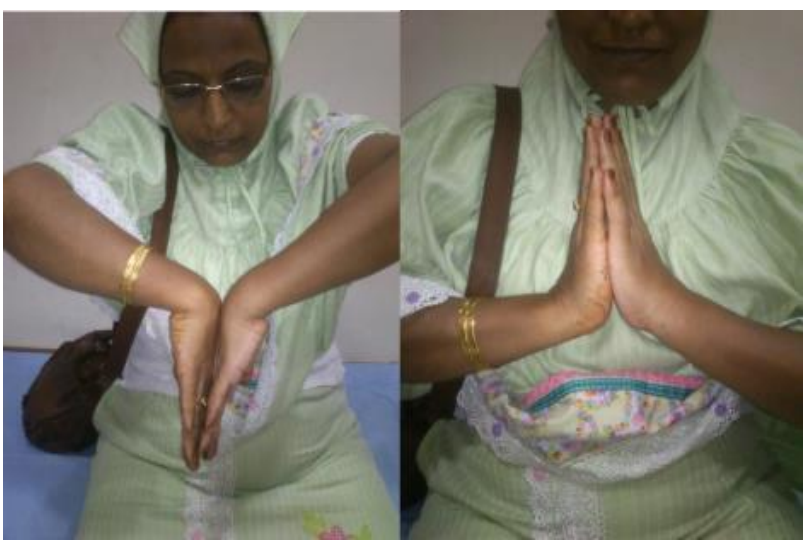

Figure 4: Post op picture showing ROM

In 14 patients (38.90\%) fracture got united within 10 weeks of time. The range of union time varied from 6 weeks to 14 weeks. The average mean for the sample of 36 patients worked out to be 9.53 weeks. Out of 36 patients, 1 patient $(2.80 \%)$ required implant removal because of pain due to longer screw at dorsum of wrist.

In our study 24 patients $(66.67 \%)$ achieved dorsi flexion between $61^{\circ}$ to $90^{\circ} .14$ patients $(38.89 \%)$ achieved palmer flexion between $61^{\circ}$ to $90^{\circ} .34$ patients $\left(94.44 \%\right.$ ) achieved supination between $61^{\circ}$ to $90^{\circ}$, which is considered to be a good outcome. 32 patients $(89.89 \%)$ achieved could move wrist pronation ranging from $61^{\circ}$ to $90^{\circ}$. $50 \%$ achieved radial deviation more than $20^{\circ}$. $75 \%$ achieved ulnar deviation more than $26^{\circ}$. We achieved excellent results for 5 patients (13.90\%), while 27 patients (75\%) got good results.

In our study, out of 23 patients with Gartland and Werley type III lower end radius fracture, we got 14 patients with excellent outcome and 7 patients with good outcome. In our study, out of 25 patients with fixed angle locked plate used for lower end radius fracture, we got 15 patients with excellent outcome and 9 patients with good outcome. Same way, in our study, out of 10 patients with fragment specific locked plate for lower end radius fracture, we got 6 patients with excellent outcome and 2 patients with good outcome and 2 patients with fair outcome. Our 1 patient in whom dorsal plating was done, got good outcome.

Table 5: Radiological evaluation

\begin{tabular}{lccc}
\hline Parameter & $\begin{array}{c}\text { Pre- } \\
\text { Operative }\end{array}$ & $\begin{array}{c}\text { Post- } \\
\text { Operative }\end{array}$ & $\begin{array}{c}\text { Follow } \\
\text { up }\end{array}$ \\
\hline $\begin{array}{l}\text { Mean Redial } \\
\text { Length (in mm) }\end{array}$ & 5.14 & 9.83 & 9.61 \\
$\begin{array}{l}\text { Mean Volar Tilt } \\
\left(\text { in }^{\circ} \text { ) }\right.\end{array}$ & 2.89 & 4.89 & 4.22 \\
$\begin{array}{l}\text { Mean Radial } \\
\text { Inclination (in }\end{array}{ }^{\circ}$ ) & 10.97 & 22.47 & 21.53 \\
\hline
\end{tabular}

Table 6: Complications

\begin{tabular}{llc}
\hline & & Frequency \\
\hline Early & Wound Infection- & \\
Complications & Hypertrophic scar & 1 \\
& Acute Carpal Tunnel & \\
& Syndrome & 0 \\
& Compartment Syndrome & 0 \\
Late & N. V. Damage & 0 \\
Complications & Loss of Reduction & 3 \\
& DRUJ Tenderness & 8 \\
& Wrist Arthrosis & 0 \\
& CRPS & 1 \\
& Non Union & 0 \\
& Tenosynovitis/ Tendon & \\
& Adhesion & 11 \\
& EPL Rupture & 0 \\
& Hardware Related & 4 \\
\hline
\end{tabular}

Table 7: Gartland and Werleys total score

\begin{tabular}{lcc}
\hline GWC RESULTS - Total Score & Frequency & Percent \\
\hline $\mathbf{0}$ & 5 & 13.90 \\
$\mathbf{2}$ & 16 & 44.40 \\
$\mathbf{3}$ & 9 & 25.00 \\
$\mathbf{4}$ & 2 & 5.60 \\
$\mathbf{5}$ & 1 & 2.80 \\
$\mathbf{1 0}$ & 2 & 5.60 \\
$\mathbf{1 2}$ & 1 & 2.80 \\
Total & 36 & 100.00 \\
\hline
\end{tabular}

Table 8: Final results

\begin{tabular}{lcc}
\hline GWC FINAL RESULTS & Frequency & Percent \\
\hline Excellent & 21 & 58.30 \\
Good & 12 & 33.30 \\
Fair & 3 & 8.30 \\
Poor & 0 & - \\
Total & 36 & 100.00 \\
\hline
\end{tabular}


Table 9: Types of plate used and their results

\begin{tabular}{lcccc}
\hline & Excellent & Good & Fair & Poor \\
\hline Locked plate with type I fracture & 2 & 3 & 0 & 0 \\
Locked plate with type II fracture & 1 & 0 & 0 & 0 \\
Locked plate with type III fracture & 12 & 6 & 1 & 0 \\
Fragment specific plate plate with type I fracture & 2 & 0 & 0 & 0 \\
Fragment specific plate with type II fracture & 2 & 1 & 0 & 0 \\
Fragment specific plate with type III fracture & 2 & 1 & 2 & 0 \\
Dorsal locked plate with type III fracture & 0 & 1 & 0 & 0 \\
\hline
\end{tabular}

\section{DISCUSSION}

Distal radius fractures are more common in young and middle aged (20 to 59 years) males who had sustained high velocity trauma (RTA). Intra- articular, displaced fracture is more common than extra articular fracture, due to high velocity trauma.

Distal radius fractures in our study, involves distal ulna fracture on same side in half of cases, of which ulna styloid is most commonly fractured. This indicates that, distal radius fracture endangers stability of distal radio-ulnar joint.

Out of 23 type III cases in our study, we used variable angled locking plates in 10 to hold radial styloid fragment, additional fixation in the form of kirschner wire in 5 patients $(13.89 \%)$ to support radial column while using conventional plates. This is due to financial reason. We got 5 patients $(13.90 \%)$ with no pain, no disability and no limitation of movements. They were rated excellent outcome of subjective evaluation in Gartland and Werley's demerit score for evaluation of distal radius fracture outcome. In a study done by $\mathrm{H}$. Drobetz, $42 \%$ patients had excellent outcome. ${ }^{4}$ Our 27 patients $(75 \%)$ had occasional pain, no disability and slight limitation of movements. These patients were rated as good outcome of subjective evaluation in Gartland and Werley's demerit score for evaluation of distal radius fracture outcome. Thus, our 32 patients (88.90\%) had satisfactory results while in a study done by $\mathrm{H}$. Drobetz, $78 \%$ patients had satisfactory outcome. ${ }^{4}$ Our 4 patients $(11.10 \%)$ had fair to poor outcome whereas, study done by $\mathrm{H}$. Drobetz had $22 \%$ fair to poor outcome. The commonest complication reported was Tenosynovitis/ Tendon Adhesion (11 cases). The other common complications found were 8 cases of DRUJ Tenderness and 4 cases had hardware related complains We have got 28 patients $(77.77 \%$ ) with various types of complications when compared to $48 \%$ complication rate 5 [Dominique Knight et al. 2010]. Tenosynovitis was related to direct attritional damage of the tendon caused by the prominent edge of the plate or by protruding screw tips. Study of Rampoldi $\mathrm{M}$, showed tendon related complications were most frequently seen. 6

Out of 14 patients with ulna styloid fracture on same side, we got 8 patients with excellent outcome and 5 patients with good outcome. The fair results were due to incomplete primary reduction with the persistence of incongruity of the radio-carpal and the distal radio-ulnar joints, incomplete restoration of radial length and malalignment of distal radial fracture fragments and due to complication like CRPS. In our study, mean final score according to Gartland and Werley's Demerit Scoring System for the result of plating of fracture of lower end radius was 2.89, that means majority of our patients get excellent to good results. A total of 21 patients $(58.30 \%)$ had excellent and $12(33.33 \%)$ had good results, but in $3(8.33 \%)$ the outcome was fair. Our outcome is comparable to that of Jupiter ${ }^{7}$ and markus figl. ${ }^{8}$

\section{CONCLUSION}

Volar locked plates in distal radial fractures can be applied to differing patterns of the fracture. Stable subchondral support to the intact radial shaft affords excellent fracture stability and prevents settling. ${ }^{7}$ It allows early active wrist motion, so less stiffness of fingers and wrist joint. Majority of complications of distal radius fracture treated by locked plating are tendon related complications. Patients have good outcome provided that correct and precise surgical technique is used, proper anatomical reduction of articular fragment and buttressing with locking plates are done and a final C-Arm check to ensure proper placement of plate and to ensure no intraarticular screw penetration and early mobilization with proper physiotherapy is done. Locking plate used for fixation of type III, that is, intra-articular, displaced, lower end radius fracture, gives excellent to good result.

\section{REFERENCES}

1. Jupiter JB. Current concepts review. Fractures of the distal end of the radius. J Bone Joint Surg [Am) 1991; 73-A: 461-9.

2. Owen RA, Melton LI ifi et al. Incidence of Colles' fracture in a North American Community. Am J Public Health 1982; 72:605-7.

3. Gartland JJ, Werley CW (1951) Evaluation of healed Colles' fractures. J Bone Jt Surg 33-A: 895-907.

4. Dominique Knight, Carol Hajducka, Elizabeth Will, Margaret McQueen. Locked volar plating for unstable distal radial fractures: Clinical and radiological outcomes Injury 2010;41(2),184-9.

5. H. Drobetz, E. Kutscha-Lissberg. Osteosynthesis of distal radial fractures with a volar locking screw plate system. International Orthopaedics (SICOT) (2003) 27:1-6

6. Rampoldi M, Marsico S. Complications of volar plating of distal radius fractures. Acta orthop Belg. 2007 Dec; 73(6):714-9.

7. Jupiter JB, Fernandez MD, choon-laui Toh at al. Operative treatment of volar intraarticular fractures of the distal end radius. J. Bone Joint surgery Am: 78:1817- 28, 1996.

8. Markus Figl, Patrick Weninger et al. Volar fixed-angle plate osteosynthesis of unstable distal radius fractures: 12 months results. Arch Orthop Trauma Surg (2009) 129:661-69.

9. Handoll HH, Madhok R. Surgical interventions for treating distal radial fractures in adults. Cochrane Database Syst Rev 2001; (3): CD003209.

\section{Source of Support: Nil. Conflict of Interest: None Declared.}

Copyright: (c) the author(s) and publisher. IJMRP is an official publication of Ibn Sina Academy of Medieval Medicine \& Sciences, registered in 2001 under Indian Trusts Act, 1882. This is an open access article distributed under the terms of the Creative Commons Attribution Non-commercial License, which permits unrestricted noncommercial use, distribution, and reproduction in any medium, provided the original work is properly cited.

Cite this article as: Sanjeev Kumar, Ritesh Kumar, Bhupesh Patel. Locking Plate Osteosynthesis for Distal Radius Fractures. Int J Med Res Prof. 2018 Nov; 4(6):248-51. DOI:10.21276/ijmrp.2018.4.6.054 